\title{
An Individual, Community-Based Treatment for Obese Children and Their Families: The Solution-Focused Approach
}

\author{
Felix Kreier Şükrü M. Genco Maggie Boreel Mieke P. Langkemper \\ Ineke C. Nugteren Viola Rijnveld Vivianne Thissen Sonja Deden \\ Marina Keessen \\ Department of Pediatrics, Onze Lieve Vrouwe Gasthuis, Amsterdam, The Netherlands
}

\section{Key Words}

Obesity - Obesity therapy · Children · Solution-focused therapy · Community-based treatment

\begin{abstract}
Background: This study evaluates an individual, community-based treatment for obese children and their families. In this program, a treatment team applied solution-focused techniques to develop a custom-made treatment plan in collaboration with the participants. The treatment plan consisted of community-based lifestyle activities. Methods: 559 obese children with an average BMI z-score of $2.76 \pm 0.54$ took part in the 12-month study, and 372 children with an average BMI z-score of $2.75 \pm 0.52$ took part in the 24-month study. At the start of the study, ethnicity and special school needs were recorded. Before, after 12 months, and after 24 months of the treatment, body weight and height were measured. The effect of the treatment on body weight was evaluated using BMI z-scores. Results: 291 children (52\%) completed 12 months of treatment, whereas 22 children (4\%) were dismissed earlier due to a good response. After 12 months, the children showed a significant decrease in BMI z-score by 0.16 (95\% confidence interval (CI) $0.11-0.20 ; p<0.005)$. After 24 months, 103 children (28\%) were participating in the program, with a significant decrease in BMI z-score of $0.15(95 \% \mathrm{CI}$ $0.07-0.22 ; p<0.005) .50$ children (13\%) were dismissed before the end of the second year due to significant weight loss (standard deviation z-score reduction $-0.38 ; 95 \%$ CI $0.30-0.46$; $p<$ 0.005 ; with an average treatment duration of $12.9 \pm 6.4$ months). There was a negative correlation of age and reduction in BMI z-score: children younger than 6 years showed a decrease in BMI z-score of 0.45 (95\% CI 0.26-0.65) and 0.31 (95\% CI 0.11-0.53) after 12 and after 24 months, respectively. Conclusions: Children showed a significant decrease in BMI z-score after the treatment. We found a negative correlation of age and weight loss. Special attention to patients with a high risk of drop-out might further improve these results. We advise a referral to obesity treatment as early as possible since a 'wait and see' policy might have adverse results in obese children.


Kreier et al.: An Individual, Community-Based Treatment for Obese Children and Their Families: The Solution-Focused Approach

\section{Introduction}

The prevalence of childhood overweight and obesity in the Netherlands has increased since the 1980s, especially in cities with a mixed population of different ethnicity, such as Amsterdam $[1,2]$. In girls aged 2-21 years, the prevalence of obesity has increased by $500 \%$ from $0.5 \%$ in 1980 to $2.2 \%$ in 2009 [1].

The treatment of childhood obesity is challenging since it demands a profound behavioral change of daily routine [3,4]. Especially the maintenance of a reduced overweight is difficult to achieve [5].

Several factors are important during an effective treatment of obese children: Firstly, combined lifestyle interventions with behavioral counseling, physical exercise, and dietary advice are more effective than fragmented therapies with only one component [6]. Secondly, brief solution-focused therapy can induce a behavioral change in the setting of various medical problems and has been successfully applied to reduce childhood obesity [5, 7-16]. Thirdly, 'close to home' treatment provided by community resources is beneficial [17].

This study evaluates an individual, community-based treatment for obese children and their families in Amsterdam. In this program, the team assisted the participants in recognizing their long-term goals and supported lifestyle changes to accomplish them. Solutionfocused techniques were applied to develop a custom-made treatment plan. In order to match the daily routine of the participants, the activities were community-based.

We hypothesized that this intervention would stabilize or reduce the BMI z-score of the children.

\section{Participants and Methods}

\section{Recruitment}

Recruitment of the participants occurred from July 2007 to May 2012 mainly via the Public Health Service of the city of Amsterdam, The Netherlands; a smaller group of children was referred by general practitioners or joined the program by self-referral. Learning disabilities were no exclusion criterion. All children that were recruited before May 2010 were enrolled in the 24-month analysis and all children recruited before May 2011 in the 12-month analysis.

\section{Treatment Program}

Medical Screening

At the first consultation, participants were screened for endocrine or syndromic causes of obesity as well as for comorbidity.

\section{Participant Assistance}

The general aim of the treatment was to assist the participants to recognize their long-term goals. The treatment focused on positive lifestyle changes in various parts of daily routines and was not necessarily restricted to weight-related behavior.

\section{Brief Solution-Focused Therapy}

At the second consultation, the special needs of each participant were explored applying the solutionfocused approach. The basic standard format was a visit every 3 weeks; however, if the participant asked for more or less visits we adjusted the individual schedule. In subsequent consultations the participant was supported to sustain the changes. We applied a variation of the problem-solving and solution-oriented methods, as described elsewhere $[5,13-15,18]$. In brief, the 30 -min consultations addressed the goals and how to overcome its barriers in maintaining eating and exercise behaviors required for sustaining lost 
Kreier et al.: An Individual, Community-Based Treatment for Obese Children and Their

Families: The Solution-Focused Approach

weight: i) The miracle question (i.e., defining the scope): 'Imagine that, while you are sleeping tonight, a miracle happens. You wake up tomorrow, and you sense that you are on track toward making a decision. What will you be doing differently that will tell you that you are on track?'; ii) exception question (i.e., uncover the participants' successes and strengths): 'Are there times now that a little piece of the miracle happens? Tell me about these times. How do you get that to happen?'; iii) coping questions (i.e., uncover concrete acts undertaken by people coping with adversity and building a foundation to find solutions): 'How are you preventing things from getting worse?'; iv) scaling questions (i.e., making vague participant perceptions concrete and definable): 'On a scale of 1 to 10 , how important is the problem for you?'; and v) implementation and evaluation (i.e., trying out a plan and evaluating its effectiveness): 'What solution plan are you going to try, and how will you know if it works?'. The participant decides together with the obesity coach on the needed frequency of sessions in order to reach the goals.

\section{Custom-Made, Community-Based Treatment Plan}

Employing the solution-oriented technique, a custom-made treatment plan was developed by the participant and the team. The activities included behavioral, dietary and sports interventions. Special attention was paid to logistic aspects in order to align the activity with the needs of the participant and its family, such as daily schedule, home and activity address, etc. The activities were community-based in several local initiatives, independent from the clinical setting. Transfer policies were developed in collaboration with the municipal authorities of the City of Amsterdam.

\section{Treatment Team}

The team consisted of various disciplines. Two pediatricians with training in solution-focused therapy ran a medical screening and conducted interviews to define the main goals of the treatment. Two obesity coaches, having been trained and supervised by the pediatricians and psychologists of the group, assisted the participants to translate these goals into their daily routine. They also maintained contact with community-based activities. During the consultations, the psychologists further consolidated the focus on long-term goals if significant pedagogical problems or a DSM-IV-TR diagnosis were suspected. Communitybased family coaches helped the participants in their daily routine at home (between one and three visits), if necessary.

\section{Outcome Measures}

Before, after 12 months, and after 24 months of the treatment, first and last available height and weight were measured and used to calculate BMI z-scores. The difference in BMI z-score was defined as primary outcome. BMI z-score was calculated according to the results of the Forth National Growth Study by the Netherlands Organization for Applied Scientific Research (TNO), using the software program Growth Analyzer (3.5) [19].

\section{Statistical Analysis}

To test the difference in SDS (standard deviation score) z-score reduction after 12 and 24 months, the variables for analysis derived from the measurements as described above. The group differences in BMI z-score and SDS z-score reduction (between gender, age groups, and ethnicity) were visualized with a box plot. Continuous variables with normal distributions are expressed as means \pm standard deviation (SD) and were compared with the use of a paired Student's t-test. The chi-square test was performed to test the distribution of gender and ethnicity between children that completed versus children that did not complete the study. To test distribution of age, BMI, and BMI z-score between these groups an independent samples t-test was performed.

A Welch's ANOVA and Games-Howell post-hoc analysis were performed. Statistical significance was defined as $\mathrm{p}<0.05$. We used SPSS version 20 (SPSS Inc., Chicago, IL, US) for the statistical calculations. 
Kreier et al.: An Individual, Community-Based Treatment for Obese Children and Their Families: The Solution-Focused Approach

Table 1. Ethnicity if $>12$ or $>24$ months in the study: Uneven distribution between ethnicity of subjects that completed versus not completed the study for 12 months. More Turkish and Moroccan children and less Surinam/Caribbean children completed the study than expected. There was no difference in Dutch children. There was a significant difference in completing the study for the different ethnicities $(\mathrm{p}<0.03$ after 12 months vs. $\mathrm{p}<0.02$ after 24 months)

\begin{tabular}{llllllll}
\hline Ethnicity & \multicolumn{2}{l}{ At start if $>12$ months in study } & & \multicolumn{2}{l}{ At start if $>24$ months in study } \\
\cline { 2 - 3 } & $\begin{array}{l}\text { total } \\
(\mathrm{N}=559)\end{array}$ & $\begin{array}{l}\text { completed } \\
(\mathrm{N}=291)\end{array}$ & $\begin{array}{l}\text { not completed } \\
(\mathrm{N}=268)\end{array}$ & & $\begin{array}{l}\text { total } \\
(\mathrm{N}=372)\end{array}$ & $\begin{array}{l}\text { completed } \\
(\mathrm{N}=103)\end{array}$ & $\begin{array}{c}\text { not completed } \\
(\mathrm{N}=269)\end{array}$ \\
\hline Dutch & $64(11 \%)$ & $32(11 \%)$ & $32(12 \%)$ & & $41(11 \%)$ & $8(8 \%)$ & $33(12 \%)$ \\
Moroccan & $118(21 \%)$ & $71(24 \%)$ & $47(18 \%)$ & & $81(22 \%)$ & $35(34 \%)$ & $46(17 \%)$ \\
Turkish & $100(18 \%)$ & $60(21 \%)$ & $40(15 \%)$ & & $81(22 \%)$ & $24(23 \%)$ & $57(21 \%)$ \\
Caribbean & $98(18 \%)$ & $42(14 \%)$ & $56(21 \%)$ & & $65(18 \%)$ & $16(16 \%)$ & $49(18 \%)$ \\
Other & $107(19 \%)$ & $48(17 \%)$ & $59(22 \%)$ & & $63(17 \%)$ & $12(12 \%)$ & $51(19 \%)$ \\
Missing & $72(13 \%)$ & $35(12 \%)$ & $37(14 \%)$ & & $41(11 \%)$ & $8(8 \%)$ & $33(12 \%)$ \\
\hline
\end{tabular}

Table 2. Gender, age, BMI, and BMI z-score if $>12$ or $>24$ months in the study. There was no difference in gender ( $p=0.12$ after 12 months vs. $\mathrm{p}=0.57$ after 24 months) and BMI z-score between children that completed versus not completed the study ( $p=0.61$ after 12 months and $p=0.55$ after 24 months). However, children that completed the study tended to be younger ( $\mathrm{p}=0.07$ after 12 months and $\mathrm{p}<0.05$ after 24 months)

\begin{tabular}{|c|c|c|c|c|c|c|c|c|c|c|}
\hline & \multicolumn{5}{|c|}{ At start if $>12$ months in study } & \multicolumn{5}{|c|}{ At start if $>24$ months in study } \\
\hline & $\begin{array}{l}\text { total } \\
(\mathrm{N}=559)\end{array}$ & $\begin{array}{l}\text { completed } \\
(\mathrm{N}=291)\end{array}$ & $\begin{array}{l}\text { not completed } \\
(\mathrm{N}=268)\end{array}$ & SE & $\begin{array}{l}\mathrm{p} \\
\text { value }\end{array}$ & $\begin{array}{l}\text { total } \\
(\mathrm{N}=372)\end{array}$ & $\begin{array}{l}\text { completed } \\
(\mathrm{N}=103)\end{array}$ & $\begin{array}{l}\text { not completed } \\
(\mathrm{N}=269)\end{array}$ & SE & $\begin{array}{l}\mathrm{p} \\
\text { value }\end{array}$ \\
\hline Male & 257 (46\%) & $138(46 \%)$ & $119(44 \%)$ & & 0.12 & $161(43 \%)$ & $47(46 \%)$ & $114(42 \%)$ & & 0.57 \\
\hline Age, years & $9.6 \pm 3.4$ & $9.3 \pm 3.2$ & $9.8 \pm 3.6$ & \pm 0.29 & 0.07 & $10.1 \pm 3.4$ & $9.1 \pm 2.9$ & $10.5 \pm 3.4$ & \pm 0.38 & 0.05 \\
\hline BMI & $27.4 \pm 5.4$ & $26.9 \pm 4.9$ & $27.9 \pm 5.8$ & \pm 0.45 & 0.05 & $27.5 \pm 5.4$ & $26.3 \pm 4.4$ & $28.0 \pm 5.7$ & \pm 0.62 & $<0.05$ \\
\hline BMI z-score & $2.76 \pm 0.54$ & $2.75 \pm 0.51$ & $2.77 \pm 0.57$ & \pm 0.05 & 0.61 & $2.75 \pm 0.52$ & $2.73 \pm 0.51$ & $2.77 \pm 0.52$ & \pm 0.06 & 0.55 \\
\hline
\end{tabular}

\section{Results}

\section{Basic Group Characteristics}

In May 2012, 559 children had started the treatment 12 months ago, and 372 children had enrolled 24 months ago (tables 1, 2).

In the 12-month group, 302 (54\%) were girls and 257 (46\%) were boys. The average age at the start of the study was $9.6 \pm 3.4$ years. $11 \%$ of the children were Dutch, $21 \%$ were Moroccan, $18 \%$ were Turkish, $10 \%$ were of other ethnic background, and in $13 \%$ of the cases ethnicity data were missing (table 1). The average BMI was $27.4 \pm 5.4 \mathrm{~kg} / \mathrm{m}^{2}$ and the average BMI z-score was $2.76 \pm 0.54$.

\section{Completers versus Non-Completers}

An uneven distribution between the ethnicity of subjects that completed versus did not complete the study after 12 months was noticed (tables 1, 2): More Turkish and Moroccan 
Kreier et al.: An Individual, Community-Based Treatment for Obese Children and Their Families: The Solution-Focused Approach

Fig. 1. Total reduction of BMI zscore after 12 months and after 24 months $(\mathrm{p}<0.005)$.

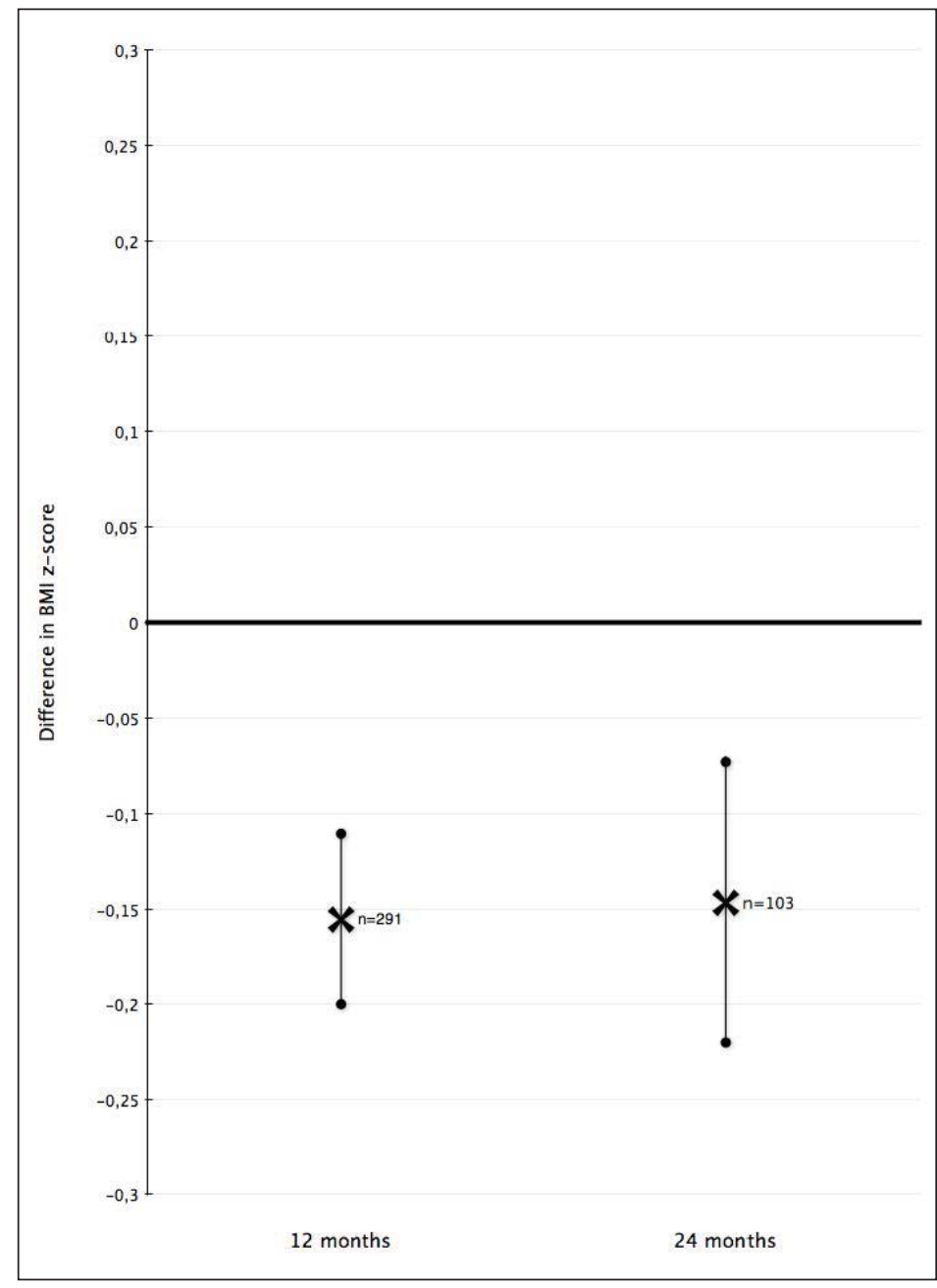

children and less Surinamese/Caribbean children completed the study than expected. There was no difference in Dutch children. There was a significant difference in completing the study for the different ethnicities ( $p<0.03$ after 12 months vs. $12.8 \mathrm{p}<0.02$ after 24 months).

There was no difference in gender ( $p=0.12$ after 12 months vs. $p=0.57$ after 24 months) and BMI z-score between children that completed versus did not complete the study $(\mathrm{p}=0.61$ after 12 months and $\mathrm{p}=0.55$ after 24 months). However, children that completed the study tended to be younger ( $p=0.07$ after 12 months and $p<0.05$ after 24 months).

\section{BMI z-Score after 12 Months}

291 children (52\%) were actively participating after 12 months of treatment (fig. 1). The average number of visits was $8.9 \pm 6.6$. Early responders $(n=22 ; 4 \%)$ were dismissed due to a significant weight loss (SD z-score reduction -0.30; 95\% confidence interval (CI) 0.22-0.39; $\mathrm{p}<0.005$ ) within the first year, after an average treatment duration of $9.5 \pm 1.5$ months. Also, in the children that completed the 12 -month period, the BMI z-score was significantly reduced from a mean of 2.75 at the start to 2.59 at 12 months or later; i.e., a reduction by $0.16 \mathrm{BMI}$ 
Kreier et al.: An Individual, Community-Based Treatment for Obese Children and Their

Families: The Solution-Focused Approach

z-score $(95 \%$ CI $0.11-0.20 ; p<0.005)$. Children younger than 6 years $(n=37)$ showed a BMI $\mathrm{z}$-score decrease of 0.45 (95\% CI 0.26-0.65; $\mathrm{p}<0.005)$, children between 6 and 11 years ( $\mathrm{n}=$ 152) 0.12 (95\% CI 0.07-0.17; $\mathrm{p}<0.005)$, and children older than 11 years $(\mathrm{n}=102) 0.10$ (95\% CI $0.04-0.17 ; \mathrm{p}<0.006)$. BMI z-score reduction differed significantly between children younger than 6 years and the other age groups (6-11 years and older than 11 years), as assessed by Welch's ANOVA $(\mathrm{F}(2,29)=7.94 ; \mathrm{p}<0.005)$ and Games-Howell post-hoc analysis ( $p=0.004$ and $p=0.005$, respectively).

\section{BMI z-Score after 24 Months}

103 children (28\%) were actively participating after 24 months of treatment (fig. 1). The average number of visits was $13.4 \pm 8.4$. Of this group, 50 children (13\%) were dismissed before the end of the second year due to significant weight loss (SD z-score reduction -0.38 ; $95 \%$ CI $0.30-0.46 ; \mathrm{p}<0.005$ ). The average treatment duration was $12.9 \pm 6.4$ months. Furthermore, in the children that completed the 24-month period the BMI z-score was significantly decreased from a mean of 2.73 at the start to 2.59 at 12 months or later; i.e., a reduction by $0.15 \mathrm{BMI} z$-score $(95 \% \mathrm{CI} 0.07-0.23$; $\mathrm{p}<0.005)$. Children younger than 6 years ( $\mathrm{n}=17$ ) showed a BMI z-score decrease of 0.31 (95\% CI 0.08-0.53; $\mathrm{p}=0.01$ ), children between 6 and 11 years $(\mathrm{n}=60) 0.10(95 \%$ CI 0.01-0.19; $\mathrm{p}=0.03)$, and children older than 11 years $(\mathrm{n}=26) 0.15(95 \%$ CI $0.01-0.32 ; \mathrm{p}=0.07)$. BMI z-score reduction was not significantly different between the age groups, as assessed by Welch's ANOVA and Games-Howell post-hoc analysis.

There was no significant difference in the effectiveness of the treatment between genders or different ethnical background.

\section{Conclusions}

Obese children and families that received the individual, community-based treatment applying solution-focused techniques showed a significant reduction in BMI z-score. The reduction in BMI z-score is slightly more beneficial than the average results of childhood obesity programs, as documented by a recent Cochrane systematic review [6].

Interestingly, there was a negative correlation of age and effect of the treatment. Younger children showed a greater loss in BMI z-score than older children. Especially children younger than 6 years reacted favorably to the treatment. This finding is in agreement with recent literature that demonstrates that obesity interventions at preschool age are effective [20,21]. These results emphasize that a 'wait and see' routine in preschool age obesity is not appropriate and that the earlier the child is transferred to treatment, the better its effect is.

We did not find significant differences in treatment effect between ethnic groups. The advantage of an individual, solution-focused approach is that the treatment is also being adjusted to ethnic background. The participant finds its solution in their cultural context. While basic knowledge of the different ethnic backgrounds is needed by the treatment team, detailed knowledge of all aspects of the individual culture is not necessary. This study demonstrates its value of this approach in a multi-ethnic setting.

The aim of interventions addressing childhood obesity is the reduction in relative risk to develop significant comorbidity. At the same time, weight reduction in childhood obesity is difficult to achieve. However, several studies showed a significant improvement in cardiovascular risk factors even after a modest decrease in BMI z-score [22, 23]. 
Kreier et al.: An Individual, Community-Based Treatment for Obese Children and Their

Families: The Solution-Focused Approach

A second aim of this study was to reveal factors that can improve childhood obesity therapy. In agreement with studies conducted elsewhere, we found a high dropout rate in our study [6]. In order to improve compliance, we have recently implemented the usage of short text messages in our program since these have been shown to improve adherence to the treatment [24, 25]. In this study, patients were dismissed after three 'no-shows'. We will implement a call by a member of the treatment team after the first missed visit. Compliance might also be ameliorated by special attention to patients with characteristics known for a treatment failure, such as irregular eating pattern, older age, and broken families [26]. Finally, many studies emphasize the importance of a family approach [27-37]. The greater effect of treatment in children younger than 6 years illustrates the importance of participation of the parents in the process. In conclusion, family involvement is an important part of childhood obesity therapy.

To achieve an increase in family involvement, a closer collaboration between the players in childhood obesity treatment is necessary. We propose that a joint operation of obesity coaches, general practitioners, and clinical pediatricians during shared consultation hours in community-based health centers will improve the participation of the family. Today, in the Netherlands, the transfer of patients between the community health centers, the general practitioner, and pediatricians means a transfer between different organizations and locations. Joined consultation hours might improve childhood obesity care by decreasing organizational barriers while being as close to the living space of the family as possible.

In conclusion, this study shows a significant reduction in BMI z-score during a 12- and 24-month treatment of obese children on the basis of an individual, community-based treatment applying solution-focused techniques. By means of a joint operation of the players in childhood obesity therapy and an intensified effort regarding patients with a high risk of dropout, the results might be further improved.

\section{Shortcomings of the Study}

Shortcomings of the study are the lack of a control group due to its design and the missing data from participants that did not finish the complete treatment period. Due to these shortcomings the study might fail to detect any rebound effects in the group of subjects that dropped out of the study, or changes in weight by external lifestyle factors.

\section{Acknowledgements}

We would like the thank A.A.M.W. Van Kempen (MD, PhD) for her advice during the conduction of the study and for correcting the manuscript. We would like to thank L.M. Dijksman (MSc) for her statistical advice.

\section{Disclosure Statement}

The authors state that there is no conflict of interest concerning this manuscript. 
Kreier et al.: An Individual, Community-Based Treatment for Obese Children and Their Families: The Solution-Focused Approach

\section{References}

1 Schönbeck Y, Talma H, van Dommelen P, et al: Increase in prevalence of overweight in Dutch children and adolescents: a comparison of nationwide growth studies in 1980, 1997 and 2009. PLoS One 2011;6:e27608.

$\checkmark 2$ de Wilde JA, van Dommelen P, Middelkoop BJC, Verkerk PH: Trends in overweight and obesity prevalence in Dutch, Turkish, Moroccan and Surinamese South Asian children in the Netherlands. Arch Dis Child 2009;94: 795-800.

3 Reinehr T: Effectiveness of lifestyle intervention in overweight children. Proc Nutr Soc 2011;70:494-505.

$\checkmark 4$ Latzer Y, Edmunds L, Fenig S, et al: Managing childhood overweight: behavior, family, pharmacology, and bariatric surgery interventions. Obesity (Silver Spring) 2009;17:411-423.

5 Perri MG, Nezu AM, McKelvey WF, et al: Relapse prevention training and problem-solving therapy in the longterm management of obesity. J Consult Clin Psychol 2001;69:722-726.

6 Oude Luttikhuis H, Baur L, Jansen H, et al: Interventions for treating obesity in children. Cochrane Database Syst Rev 2009;(1):CD001872.

7 Nezu AM, Ronan GF: Life stress, current problems, problem solving, and depressive symptoms: an integrative model. J Consult Clin Psychol 1985;53:693-697.

8 Teismann MW: Jealousy: systematic, problem-solving therapy with couples. Fam Process 1979;18:151-160.

-9 Maljanen T, Paltta P, Harjanen T, et al: The cost-effectiveness of short-term psychodynamic psychotherapy and solution-focused therapy in the treatment of depressive and anxiety disorders during a one-year followup. J Ment Health Policy Econ 2012;15:13-23.

10 Vogelaar L, Van't Spijker A, Vogelaar T, et al: Solution focused therapy: a promising new tool in the management of fatigue in Crohn's disease patients. J Crohns Colitis 2011;5:585-591.

11 Klar H, Coleman WL: Brief solution-focused strategies for behavioral pediatrics. Pediatr Clin North Am 1995; 42:131-141.

12 Murawski ME, Milsom VA, Ross KM, et al: Problem solving, treatment adherence, and weight-loss outcome among women participating in lifestyle treatment for obesity. Eat Behav 2009;10:146-151.

13 Greenberg G, Ganshorn K, Danilkewich A: Solution-focused therapy. Counseling model for busy family physicians. Can Fam Physician 2001;47:2289-2295.

14 Chandler MC, Mason WH: Solution-focused therapy: an alternative approach to addictions nursing. Perspect Psychiatr Care 1995;31:8-13.

15 De Shazer S, Berg IK, Lipchik E, et al: Brief therapy: focused solution development. Fam Process 1986;25: 207-221.

16 Miller G, De Shazer S: Emotions in solution-focused therapy: a re-examination. Fam Process 2000;39:5-23; discussion 25-28.

$\checkmark 17$ Economos CD, Hyatt RR, Goldberg JP, et al: A community intervention reduces BMI z-score in children: Shape Up Somerville first year results. Obesity (Silver Spring) 2007;15:1325-1336.

-18 Perri MG, Limacher MC, Durning PE, et al: Extended-care programs for weight management in rural communities: the treatment of obesity in underserved rural settings (TOURS) randomized trial. Arch Intern Med 2008; 168:2347-2354.

19 Fredriks AM, van Buuren S, Wit JM, Verloove-Vanhorick SP: Body index measurements in 1996-7 compared with 1980. Arch Dis Child 2000;82:107-112.

20 Brotman LM, Dawson-McClure S, Huang KY, et al: Early childhood family intervention and long-term obesity prevention among high-risk minority youth. Pediatrics 2012;129:e621-628.

21 Hesketh KD, Campbell KJ: Interventions to prevent obesity in 0 -5 year olds: an updated systematic review of the literature. Obesity (Silver Spring) 2010;18(suppl 1):S27-35.

22 Kolsgaard MLP, Joner G, Brunborg C, et al: Reduction in BMI z-score and improvement in cardiometabolic risk factors in obese children and adolescents. The Oslo Adiposity Intervention Study - a hospital/public health nurse combined treatment. BMC Pediatr 2011;11:47.

-23 Grulich-Henn J, Lichtenstein S, Hörster F, et al: Moderate weight reduction in an outpatient obesity intervention program significantly reduces insulin resistance and risk factors for cardiovascular disease in severely obese adolescents. Int J Endocrinol 2011;2011:541021.

24 de Niet J, Timman R, Bauer S, et al: Short message service reduces dropout in childhood obesity treatment: a randomized controlled trial. Health Psychol 2012;31:797-805.

-25 Nguyen B, Kornman KP, Baur LA: A review of electronic interventions for prevention and treatment of overweight and obesity in young people. Obes Rev 2011;12:e298-314.

-26 de Niet J, Timman R, Jongejan M, Passchier J, van den Akker E: Predictors of participant dropout at various stages of a pediatric lifestyle program. Pediatrics 2011;127:e164-170.

27 Grønbaek HN, Madsen SA, Michaelsen KF: Family involvement in the treatment of childhood obesity: the Copenhagen approach. Eur J Pediatr 2009;168:1437-1447.

28 Nowicka P, Flodmark CE: Family therapy as a model for treating childhood obesity: useful tools for clinicians. Clin Child Psychol Psychiatry 2011;16:129-145.

29 Yackobovitch-Gavan M, Nagelberg N, Phillip M, et al: The influence of diet and/or exercise and parental compliance on health-related quality of life in obese children. Nutr Res 2009;29:397-404.

30 Collins CE, Okely AD, Morgan PJ, et al: Parent diet modification, child activity, or both in obese children: an RCT. Pediatrics 2011;127:619-627. 
Kreier et al.: An Individual, Community-Based Treatment for Obese Children and Their Families: The Solution-Focused Approach

-31 Young KM, Northern JJ, Lister KM, Drummond JA, O’Brien WH: A meta-analysis of family-behavioral weightloss treatments for children. Clin Psychol Rev 2007;27:240-249.

-32 Luley C, Blaik A, Aronica S, et al: Evaluation of three new strategies to fight obesity in families. J Nutr Metab 2010;2010:pii: 751905.

-33 Magarey AM, Perry RA, Baur LA, et al: A parent-led family-focused treatment program for overweight children aged 5 to 9 years: the PEACH RCT. Pediatrics 2011;127:214-222.

34 Golley RK, Hendrie GA, Slater A, Corsini N: Interventions that involve parents to improve children's weightrelated nutrition intake and activity patterns - what nutrition and activity targets and behaviour change techniques are associated with intervention effectiveness? Obes Rev 2011;12:114-130.

35 Morgan PJ, Lubans DR, Plotnikoff RC, et al: The 'Healthy Dads, Healthy Kids' community effectiveness trial: study protocol of a community-based healthy lifestyle program for fathers and their children. BMC Public Health 2011;11:876.

36 Okely AD, Collins CE, Morgan PJ, et al: Multi-site randomized controlled trial of a child-centered physical activity program, a parent-centered dietary-modification program, or both in overweight children: the HIKCUPS study. J Pediatr 2010;157:388-394; 394.e1.

37 Watson PM, Dugdill L, Pickering K, et al: A whole family approach to childhood obesity management (GOALS): Relationship between adult and child BMI change. Ann Hum Biol 2011;38:445-452. 